\title{
Mechanism of Polymerization Reaction of 4-[(n-Butylsulfinyl)methyl]-4'-(chloromethyl)benzene
}

\author{
Sang Yong Pyun, Whan Gi Kim, ${ }^{\dagger}$ Jin-Hyun Jeong, and Bong Rae Cho ${ }^{\dagger}{ }^{*}$ \\ Department of Chemistry, Pukyong National University, Pusan 608-737, Korea. "E-mail: sypyun@pkntac.kr \\ "Department of Applied Chemistry, Konkuk University, Chungiu 380-701, Korea \\ "College of Phannacy, Kning Hee University, Seoul 130-701, Korea \\ ${ }^{\$_{D}}$ pepartment of Chemistry, Korea University, Seoul 136-701, Korea. "E-mail: chobr@korea.ac.kr \\ Received October 23,2008
}

\begin{abstract}
The polymerization reaction of 4-[( $n$-butylsulfinyl)methyl]- $4^{4}$-(chloromethyl)benzene (1a) with $t$-BuONa in $\mathrm{CII}_{2} \mathrm{Cl} /$ monomethylformamide (MMF) (4/6) was studied kinetically. The reaction proceeds in two steps; the formation of a p-quinodimethane intermediate (M) followed by the polymerization of $\mathbf{M}$. Results of kinetic studies and HI-D exchange experiments reveal that the 1,6-elimination proceeds by the (Elcb) ir mechanism. The rate of the disappearance of $\mathbf{M}$ was increased by the carbanion and $\mathrm{S}_{2} \mathrm{O}_{8}{ }^{2-}$, inhibited by TEMPO and unaltered by the addition of IICl. From these results, a free radical polymerization mechanism is proposed.
\end{abstract}

Key Words : Elimination, Polymerization, Intermediate

\section{Introduction}

Conjugated polymers have been the subject of intensive research because of their potential applications in electrochemical, electronic, and optical materials.' The most intensively investigated conjugated polymers are poly(p-phenylene vinylene) (PPV) and its derivatives. ${ }^{2,3 a, 3 b,{ }^{2}}$ The standard method of preparing PPV is the polymerization of $\alpha, \alpha^{\prime}$ bis(tetrahydrothiophenio)-p-xylene dichloride with $\mathrm{OH}^{-}$ followed by thermal elimination of the resulting polymer $^{3 a, 3 b}$ Numerous papers have been published regarding the synthesis of PPV derivatives. ${ }^{4}$ In sharp contrast, much less effort was focused on the polymerization mechanism studies. ${ }^{3 c .3 d .5-8}$

There are two postulated mechanisms regarding the polymerization reactions. Wessling postulated that the reaction proceeds via $p$-xylylene intermediate followed by a free radical polymerization. ${ }^{3 c .3 d}$ Although he did not provide mechanistic evidences, this mechanism has been accepted by many investigators as a guideline for their synthesis. Later, Lahti and coworkers identified the $p$-xylylene intermediate in the reaction mixture by using the low temperature NMR and UV-vis spectroscopy. ${ }^{\text {id }}$ Based on the failure to detect the free radical intermediate, they proposed the anion mechanism for the polymerization reaction. More recently, one of us had conducted a series of extensive mechanistic studies on the polymerization reactions forming PPV precursor polymer and related compounds. ${ }^{7276}$ The results of product, H-D exchange, and kinetic studies revealed that the polymerization reaction of $\mathrm{SH}$ with $\mathrm{OH}^{-}$proceeds by the $(\text { Elcb })_{R}$ elimination-free radical polymerization mechanism as shown in Scheme 1. The validity and the microscopic rate constants of each elementary step were elucidated by independent experiments. Except for the $k_{\mathrm{p}}[\mathbb{R} \cdot]$ step, all other steps involving the consumption of $\mathbf{M}$ were found to be minor reaction pathways, which can be neglected under the synthetic condition where higher concentrations of the reactants are used. A similar mechanism was proposed for the polymerization of thiophene and furan derivatives, except that the mechanism of 1,6-elimination changed from $(\mathrm{E} 1 \mathrm{cb})_{\mathrm{R}}\left(k_{-1} \gg k_{2}\right)$ for $\mathrm{SH}$ to $(\mathrm{E} 1 \mathrm{cb})_{\text {irr }}\left(k_{-1}<<k_{2}\right)$ for the latter. ${ }^{7 c 7 d}$ The change in the elimination mechanism has been attributed to the difference in the aromatic resonance energies of the benzene and heterocycles. Because the aromatic resonance energy of the latter is much smaller than that of benzene, ${ }^{9}$ the $k_{2}$ increased to the extent that $k_{-1} \ll k_{2}$, and the mechanism changed to (E1cb) irr.

Earlier, Vaderzandte et al. developed a novel route to nonionic precursor polymers to the PPV, which are soluble in organic solvents (eq. 1). ${ }^{81.86}$ Unlike the Wessling's route which employs the sulfonium ion both as the polarizing and the leaving group in the $p$-xylene monomer, this route introduced a chemical differentiation by using either sulfon$\mathrm{yl}$ or sulfinyl group at the $\alpha$-position and halides at the $\alpha$ -

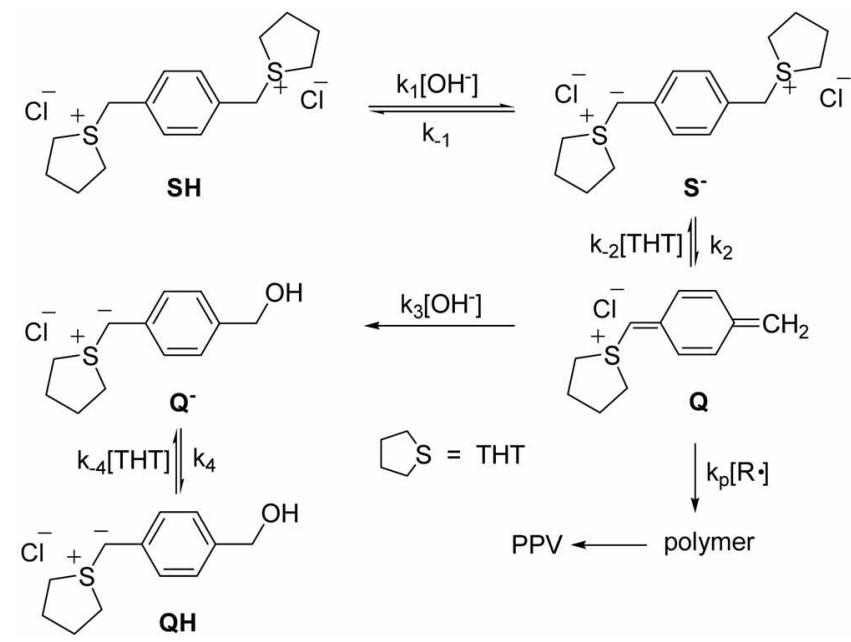

Scheme 1 
position, as the polarizer and leaving group, respectively. As reported for the Wessling's route, this reaction has been proposed to proceed in two steps. The first step was the 1,6elimination reaction forming $p$-quinodimethane intermedjate. To determine whether the 1,6-elimination reaction proceeds via the carbanion intemnediate, $4-[(n$-butylsulfinyl)methy $]-4$-(chloromethy $]$ )benzene and $4-[(n$-butylsulfonyl)methyl]-4-(chloromethyl)benzene were treated with $t$ BuOK in deuterated solvent (NMF- $d$ ) for 1 hr at $-35 \sim-45$ ${ }^{\circ} \mathrm{C}$. However, no H-D exchange was observed by NMR, indicating that there is no free carbanion intermediate. This implies a concerted E2 or $(\mathrm{E} 1 \mathrm{cb})_{\text {ir }}$ mechanism for the 1,6elimination reaction. Although the authors have employed different leaving groups to distinguish between these two possibilities, they only compared the yields and molecular weights, which did not lead to decisive conclusion.

To provide a better insight into the reaction mechanism, we have conducted a kinetic study on the polymerization reaction of $4-[(n$-butylsulfiny $)$ methyl $]-4$ '-(halomethyl)benzene with $t$ - $\mathrm{BuONa}$ in $\mathrm{CH}_{2} \mathrm{Cl}_{2} / \mathrm{MMF}(4 / 6)$ at $25.0^{\circ} \mathrm{C}$ (eq. 1). The nature of the intermediate was identified by a UV-vis spectrophotometer. Rates of elimination and polymerization pathways were measured by monitoring the increase and decrease in the intermediate concentration with reaction time, respectively. Results of the kinetic studies and H-D exchange experiments reveal that the reaction proceeds by an $(E I c b)_{\text {irr }}$ elimination to afford $p$-quinodimethane intermediate $\mathbf{M}$, followed by a free radical polymerization of $\mathbf{M}$.

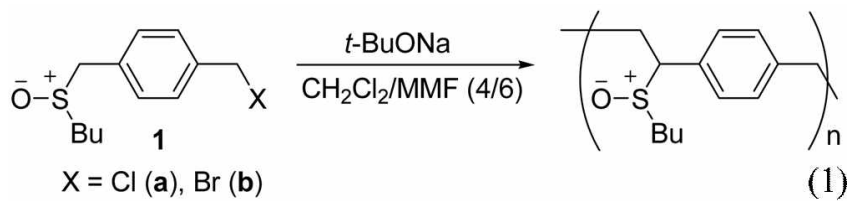

\section{Experimental Section}

Materials. 4-[(n-Butylsulfinyl)methy] $]-4$ '-(chloromethyl)benzene (1a) and 4-[(n-butylsulfinyl)methyl]-4'-(bromomethyl)benzene (1b) were prepared by known methods. ${ }^{8 a .8 b}$ The spectral and analytical data of the compounds were consistent with the proposed structures. The yield (\%), melting points $\left({ }^{\circ} \mathrm{C}\right), \mathrm{IR}(\mathrm{KBr}), \mathrm{NMR}\left(400 \mathrm{MHz}, \mathrm{CDCl}_{3}\right)$ and mass spectral data for these compounds are listed in Figures SI-S6 in the Supporting Infornation. MMF was purified as reported. ${ }^{8 \mathrm{k}}$ Reagent grade $t$-BuONa $(>99 \%)$ was used as purchased. The solutions of $t-\mathrm{BuONa}$ in $\mathrm{CH}_{2} \mathrm{Cl}_{2} / \mathrm{MMF}(4 / 6)$ were prepared by adding fresh $t$-BuONa to $\mathrm{CH}_{2} \mathrm{Cl}_{2} / \mathrm{MMF}$ (4/ 6 ) in a glove box. Deuterated $N$-methylformamide (MMF- $d$ ) was prepared by adding $\mathrm{D}_{2} \mathrm{O}(2 \mathrm{~mL})$ to a flask containing $\mathrm{Na}$ $(1.6 \mathrm{~g}, 0.07 \mathrm{~mol})$ in MMF $(3 \mathrm{~mL})$.

MMR Experiment. To determine whether the acidic benzylic protons of 1a undergo hydrogen-deuterium exchange, 1a was treated with $t$-BuONa in MMF- $d$ at $25^{\circ} \mathrm{C}$. The NMR spectrum of the reaction mixture was obtained after mixing 1 equiv of $1 \mathrm{a}$ to a flask containing $t$-BuONa $\left(4.0 \times 10^{-3} \mathrm{M}, 5 \mathrm{~mL}\right)$ in MMF-d. The reaction was quenched by adding dilute $\mathrm{HCl}(\mathrm{aq})$ immediately after mixing. The proton NMR spectrum of the recovered reactant was identical to that of the reactant; there was no change in the intensity of the benzylic proton peak at $\delta 3.98$ (spectrum not shown).

UV-Vis Spectrum of the Intermediate. The UV-vis spectra for the reaction of $1 \mathrm{a}$ with $t=\mathrm{BuONa}$ in $\mathrm{CH}_{2} \mathrm{Cl}_{2} / \mathrm{MMF}$ (4/ 6) were obtained by adding $1 \mathrm{a}\left(8.0 \times 10^{-5} \mathrm{M}\right)$ to a cuvette containing $t$-BuONa $\left(7.0 \times 10^{-2} \mathrm{M}, 3.0 \mathrm{~mL}\right)$ in $\mathrm{CH}_{2} \mathrm{Cl}_{2} / \mathrm{MMF}$ (4/6) at $25^{\circ} \mathrm{C}$. The spectrum was scanned periodically with time. In all cases, the absorbance first increased to a maximum and then decreased with time, indicating that the intermediate accumulated before undergoing the polymerization reaction.

Rate of Elimination Reaction. The rates of elimination reactions of 1 with $t=\mathrm{BuONa}$ in $\mathrm{CH}_{2} \mathrm{Cl}_{2} / \mathrm{MMF}(4 / 6)$ were determined by monitoring the increase of the absorbance for the internediate $\mathbf{M}$ with time at $316 \mathrm{~nm}$ with a UV-vis spectrophotometer as reported. ${ }^{7 b, 7 c}$ Because the rate of elimination reaction was much faster than that of the subsequent polymerization reaction, no problem was encountered in the rate studies. In all cases, plot of $-\ln \left(A_{\diamond}-A_{l}\right)$ versus time were linear over three half-lives of the reaction. The slope was the pseudo-first order rate constant.

Rate of Polymerization. The rates of polymerization were measured by monitoring the decrease in absorption at $316 \mathrm{~nm}$ for $M$ with a UV-vis spectrophotometer as described above.

Effects of Carbanion, $\mathrm{HCl}(\mathrm{aq}), \mathrm{S}_{2} \mathrm{O}_{8}{ }^{2-}$, and TEMPO on the Polymerization Reaction. The effects of additives on the polymerization reaction were assessed by the following procedure. A cuvette containing $t-\mathrm{BuONa}\left(7.0 \times 10^{-2} \mathrm{M}, 3.0\right.$ $\mathrm{mL}$ ) in $\mathrm{CH}_{2} \mathrm{Cl}_{2} / \mathrm{MMF}(4 / 6)$ was covered with rubber septa and purged for at least $20 \mathrm{~min}$ with nitrogen while the temperature being equilibrated prior to kinetic runs. To determine the effect of carbanion $\mathrm{CH}_{3} \mathrm{NO}_{2}(0.3 \mathrm{M}, 2 \mu \mathrm{L})$ was added to this solution with a microsyringe when the maximum concentration of $\mathbf{M}$ was accumulated. The cuvette was quickly shaken and retumed to the cuvette compartment. The decrease of the absorbance for the $\mathbf{M}$ at $316 \mathrm{~nm}$ with time was monitored. The effects of $\mathrm{HCl}(\mathrm{aq}), \mathrm{S}_{2} \mathrm{O}_{3}=$, and TEMPO were determined by the same method, except that $\mathrm{HCl}(\mathrm{aq})(12 \mathrm{M}, 17.5 \mu \mathrm{L}), 4.8 \times 10^{-2} \mathrm{M}^{2} \mathrm{~S}_{2} \mathrm{O}_{8}{ }^{2-}(0.3 \mathrm{M}$, $20 \mu \mathrm{L})$, and TEMPO $(0.01 \mathrm{M}, 4 \mu \mathrm{L})$ were used. In all cases, plots of $-\ln \left(A_{1}-A_{\infty}\right)$ versus time were linear over two halflives of the reaction. The slopes are the pseudo-first-order rate constants.

\section{Results}

4-[(n-Butylsulfiny])methy] ]-4'-(chloromethyl)benzene (1a) was prepared by the reaction of butanethiolate with $1,4-$ bis(chloromethyl)benzene followed by the oxidation as reported. ${ }^{8 a .8 b}$ Treatment of 1a with $\mathrm{LiBr}$ in 3-pentanone afforded 4-[(n-butylsulfinyl)methy] $]$-4'-(bromomethyl)benzene $\mathbf{1 b}$ in moderate yield.

The UV-vis spectra for the reaction of 1a with $t$-BuONa in $\mathrm{CH}_{2} \mathrm{Cl}_{2} / \mathrm{MMF}(4 / 6)$ at $25^{\circ} \mathrm{C}$ are depicted in Figure 1. The 


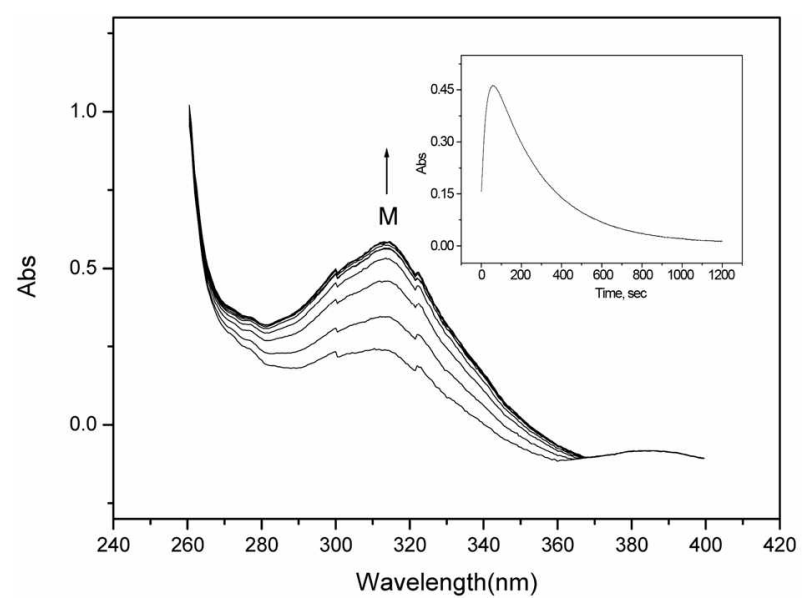

Figure 1. Change of the UV-vis spectrum with time and for the reaction of 4-[(n-butylsulfinyl)methyl]-4'-(chloromethyl)benzene (1a) with $t-\mathrm{BuONa}$ in $\mathrm{CH}_{2} \mathrm{Cl}_{2} \mathrm{MMF}(4 / 6)$ at $25.0^{\circ} \mathrm{C}$. Inset: Change of UV absorption at $316 \mathrm{~nm}$ with time for the same reaction: [1a]= $8.0 \times 10^{-5} \mathrm{M},[\imath-\mathrm{BuONa}]=7.0 \times 10^{-2} \mathrm{M}$.

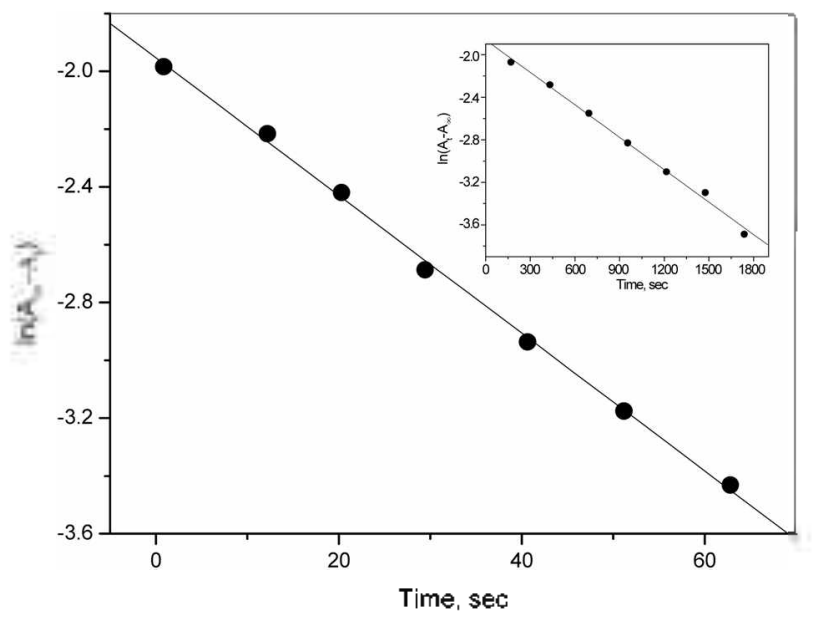

Figure 2. Plot of $\ln \left(\Lambda_{x}-\Lambda_{1}\right)$ vs time for the reaction of 4(chloronethyl)-4-[n-butylsulfinyl]benzene (1a) with $t$-BuONa in $\mathrm{CH}_{2} \mathrm{Cl}_{2} / \mathrm{MMF}(4 / 6)$ at $25.0^{\circ} \mathrm{C}$. Inset: Plot of $\ln \left(\mathrm{A}_{1}-\mathrm{A}_{x}\right)$ vs time for the polymerization reaction of $p$-quinodimethane intermediate $(\mathbf{M})$ with $t$-BuONa in $\mathrm{CH}_{2} \mathrm{Cl}_{2} / \mathrm{MMF}(4 / 6)$ at $25^{\circ} \mathrm{C}:[1 \mathrm{a}]=8.0 \times 10^{-5} \mathrm{M}$, $[t-\mathrm{BuONa}]=7.0 \times 10^{-2} \mathrm{M}$.

absorbance at $316 \mathrm{~nm}$ increased gradually as the reaction proceeded (Figure 1). The absorbance decreases slowly after reaching a maximum point (Figure 1, Inset). Because the rate of the former was much faster than the latter, the rates of both steps could be detemined independently.

Rates of eliminations from 1 were determined by

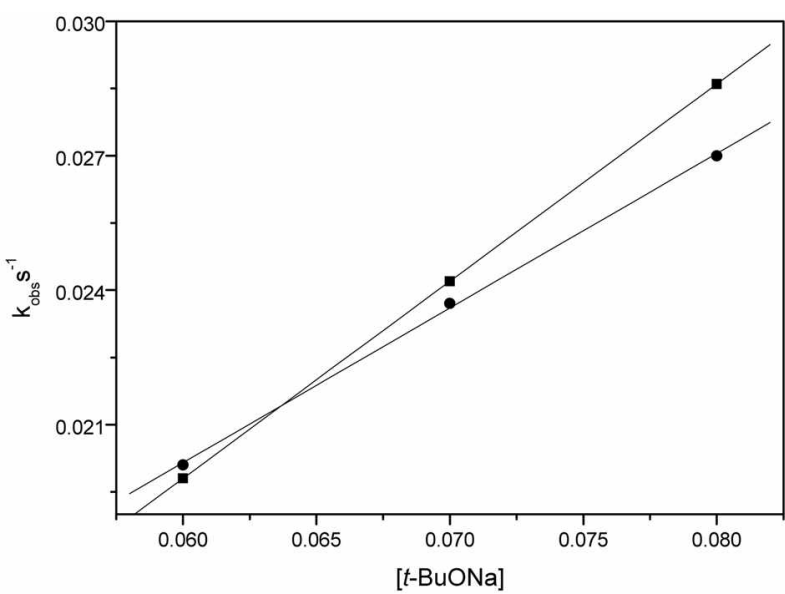

Figure 3. Plots log $k_{o b s}$ versus base concentration for clumunation reaction 4 -(halomethy]) 4 -[(n-butylsulfinyl)methyl]benzene [1a (ם) and $1 \mathrm{~b}(\bullet)]$ promoted by $t-\mathrm{BuONa}$ in $\mathrm{CH}_{2} \mathrm{Cl}_{2} / \mathrm{MMF}(4 / 6)$ at $25.0^{\circ} \mathrm{C}$

monitoring the increase in the absorbance at $316 \mathrm{~nm}$ with a UV-vis spectrophotometer (Figure 1).

Figure 2 shows the plot of $\ln \left(A_{\infty}-A_{i}\right)$ versus time for the reaction between $1 \mathrm{a}$ and $t-\mathrm{BuONa}$ in $\mathrm{CH}_{2} \mathrm{Cl}_{2} / \mathrm{MMF}(4 / 6)$. For all reactions, excellent pseudo-first-order plots were obtained for over three half-lives. The effect of base concentration on the elimination reaction could be determined in a rather limited concentration range because the kinetics was complicated due to the limited solubility of $t$-BuONa in $\mathrm{CH}_{2} \mathrm{Cl}_{2} / \mathrm{MMF}$ (4/6) when the base concentration was outside the range indicated in Table 1 . The rate constants for the elimination reactions are summarized in Table 1 .

Within this concentration range, the rate data showed firstorder dependence on $[t-\mathrm{BuONa}]$, i.e., $k_{\mathrm{obs}}{ }^{\mathrm{E}}=k_{\mathrm{c}}[t-\mathrm{BuONa}]$ and $k_{\mathrm{obs}}=k_{\mathrm{Br}}[t-\mathrm{BuONa}]$ (Figure 3 ). The second-order rate constants obtained from slopes of these plots are $k_{\mathrm{Cl}}=0.44$ and $k_{\mathrm{Br}}=0.34 \mathrm{M}^{-1} \mathrm{~s}^{-1}$, respectively.

To detemine whether the elimination reaction proceeds by the $(E 1 \mathrm{cb})_{\mathrm{R}}$ mechansim, the $\mathrm{H}-\mathrm{D}$ exchange experiment was carried out by mixing 1a with $t$-BuONa in MMF- $d$ at 25 ${ }^{\circ} \mathrm{C}$. If there were significant H-D exchange, the presence of an anion in the deuterated solvent should result in exchange of $\mathrm{H}$ into $\mathrm{D}$ at the acidic benzylic position. However, the benzylic proton resonance at $\delta 3.98$ remained nearly the same, indicating that the proton did not undergo H-D exchange. This outcome is consistent with the literature result. ${ }^{8 \mathrm{~h}}$

The rates of polymerization reaction were measured by monitoring the decrease in the absorption of the $p$-quino-

Table 1. Observed Rate Constants for Elimination $\left(k_{0 b s}{ }^{E}\right)$ and Polymerization $\left(k_{0 b s}{ }^{p}\right)$ Steps for Reactions of la and $1 b^{\prime \prime}$ with $l-B u O N a$ in $\mathrm{CH}_{2} \mathrm{Cl}_{2} \mathrm{MMF}(4 / 6)$ at $25.0^{\circ} \mathrm{C}$

\begin{tabular}{|c|c|c|c|c|}
\hline \multirow{2}{*}{$10^{2}[t-\mathrm{BuONa}], \mathrm{M}$} & \multicolumn{2}{|c|}{$10^{2} k_{0 b \mathrm{~s}}+5^{-16}$} & \multicolumn{2}{|c|}{$10^{3} k_{\text {obs }}{ }^{\mathrm{P}}, \mathrm{s}^{-1 b}$} \\
\hline & 1a & lb & 1a & $1 \mathbf{b}$ \\
\hline 6.00 & $1.98 \pm 0.02$ & $2.01 \pm 0.03$ & $0.920 \pm 0.004$ & $1.10 \pm 0.03$ \\
\hline 7.00 & $2.42 \pm 0.03$ & $2.37 \pm 0.04$ & $1.02 \pm 0.04^{\circ}$ & $1.17 \pm 0.03$ \\
\hline 8.00 & $2.86 \pm 0.02$ & $2.70 \pm 0.06$ & $1.28 \pm 0.03$ & $1.29 \pm 0.04$ \\
\hline
\end{tabular}

"[Substrate $]=8.0 \times 10^{-5} \mathrm{M} .{ }^{b}$ Average of three or more rate constants. 
Table 2. Effects of $A$ dditives on $k_{\text {obs }}{ }^{\mathrm{I}}$ for the Polymerization of Quinodimethane Intermediate $(\mathbf{M})$ at $25.0^{\circ} \mathrm{C}^{\mathrm{a}}$

\begin{tabular}{cccccc}
\hline Additives & none & $\mathrm{HCl}_{(\{\mathrm{y})}$ & $\mathrm{CH}_{3} \mathrm{NO}_{2}$ & $\mathrm{~S}_{2} \mathrm{O}_{8}{ }^{2-}$ & $\mathrm{TEMPO}$ \\
\hline Concentration, $\mathrm{M}^{h}$ & - & $7.10=10^{-2}$ & $2.00 * 10^{-2}$ & $4.80 \times 10^{-2}$ & $1.30 \sim 10^{-5}$ \\
$10^{3} k_{\text {obs }}{ }^{p} \mathrm{~s}^{-1 \mathrm{c}}$ & $1.02 \pm 0.04$ & $0.815 \pm 0.060$ & $1.50 \pm 0.03$ & $16.0 \pm 0.4$ & $0.451 \pm 0.04$ \\
\hline
\end{tabular}

${ }^{4}[\mathrm{M}] \approx 8.0 \times 10^{-5} \mathrm{M} .[t-\mathrm{BuON}$ a $]=7.0 \times 10^{-2} \mathrm{M} .{ }^{b}$ The concentrations of each additive in the cuvette containing the reactants. "Average of three or more rate constants.

dimethane intermediate $\mathbf{M}$ at $316 \mathrm{~nm}$ with a UV-vis spectrophotometer. The plots of $\ln \left(A_{1}-A_{2}\right)$ versus time were linear with excellent correlations (Figure 2, Inset). The $k_{\text {obs }}$ increased from $1.02 \times 10^{-3} \mathrm{~s}^{-1}$ to $1.50 \times 10^{-2} \mathrm{~s}^{-1}$ when $2.0 \times$ $10^{-1} \mathrm{M}$ of $\mathrm{CH}_{3} \mathrm{NO}_{2}$ was added to the solution containing $\mathbf{M}$ and base. When the solution was neutralized by adding $I$ equiv of $\mathrm{HCl}$, the $k_{0 \text { bs }}$ decreased slightly. The $k_{0 b}$ increased by more than 15 -fold by a free radical initiator $\mathrm{S}_{2} \mathrm{O}_{8}{ }^{2-}$ and decreased by half upon addition of TEMPO (Table 2).

\section{Discussion}

It was reported that the reaction of $4-[(n$-butylsulfinyl)methy]]-4'-(halomethyl)benzene (1ia) 1 with $t$-BuONa in $\mathrm{CH}_{2} \mathrm{Cl}_{2} / \mathrm{MMF}$ (4/6) proceed via $p$-quinodimethane intermediate $\mathrm{M}^{8 \mathrm{~s}}$ Figure $\mathrm{I}$ shows that the reaction of $1 \mathrm{a}$ with $t-$ $\mathrm{BuONa}$ in $\mathrm{CH}_{2} \mathrm{Cl}_{2} / \mathrm{MMF}(4 / 6)$ produces an intermediate with a strong absorption at $316 \mathrm{~nm}$, which accumulates before undergoing polymerization. Because the rate of the former was much faster than the subsequent polymerization reaction, each step could be studied independently (Figure I, Inset).

Mechanism of Elimination from 1. The first step of the polymerization reaction has been assumed to be the formation of $\mathbf{M}$. Although $\mathbf{M}$ has never been isolated due to the instability, convincing evidences for its existence have been reported ${ }^{8 \mathrm{8}}$ First, compound 2 was isolated from the reaction mixture, which has been attributed to the addition of MMF to $\mathbf{M}$. Second, 3 was isolated when 2,2,6,6-tetramethylpiperidinoxy (TEMPO) radical was added to the reaction mixture. This has been ascribed to the formation of a diradical intermediate $\mathbf{M M}$ by the coupling between two molecules of $\mathbf{M}$, followed by the subsequent coupling with TEMPO and intramolecular elimination as shown in Scheme 2. Therefore, the intermediate with a strong absorption at
$316 \mathrm{~nm}$ can most reasonably be assigned to $M$.

The mechanism of the elimination reaction was assessed by the kinetic study and H-D exchange experiment. Since the reaction exhibited second-order kinetics, all but bimolecular pathways can be ruled out. ${ }^{10}$ Hence, the most likely mechanism for this bimolecular process is either E2 or E1cb $\left[(E I c b)_{i p},(E I c b)_{R}\right.$, or $\left.(E I c b)_{i r r}\right]$. The $(E 1 c b)_{i p}$ mechanism requires the formation of an intimate ion pair between $\mathbf{1}^{-}$and the conjugate acid of the promoting base, i.e., $t-\mathrm{BuOH}$, along the reaction pathway. However, this mechanism is highly implausible because such an intermediate cannot exist in a polar solvent. Moreover, the $(\mathrm{E} 1 \mathrm{cb})_{\mathrm{R}}$ mechanism, in which $k_{-1} \gg k_{5}$ is negated by the absence of the H-D exchange of the benzylic protons of $1 .^{10}$

The distinction between the $\mathrm{E} 2$ and $(\mathrm{E} I \mathrm{cb})_{\text {ir }}$ mechanism has been made by the leaving group element effect (Table I). The $(\mathrm{EI} \mathrm{cb})_{\text {ir }}$ mechanism predicts that the $k_{\mathrm{Br}} / k_{\mathrm{Cl}}$ value should be smaller than unity because the negative charge developed at the acidic benzylic carbon in the transition state can be better stabilized by the polar or inductive effect of the chloride. ${ }^{10}$ In contrast, a much larger value of the leaving group element effect is anticipated for the E2 mechanism because the $\mathrm{C}_{c r} \mathrm{X}$ bond should be broken significantly in the transition state. Therefore, the observed $k_{\mathrm{Br}} / k_{\mathrm{Cl}}=0.77$ with $t$ BuONa-promoted elimination from $\mathbf{1}$ is consistent with an $(E I c b)_{\text {ir }}$ mechanism (Scheme 3). The change of the elimination mechanism from $(\mathrm{E} I \mathrm{cb})_{\mathrm{R}}\left(k_{-1} \gg k_{2}\right)$ to $(\mathrm{E} 1 \mathrm{cb})_{\text {in }}\left(k_{-1}\right.$ $\ll k_{2}$ ) with the reactant structure variation from SH to 1 can be attributed to the combined effects of weaker electron accepting ability of sulfiny] group $\left[\sigma_{\mathrm{p}}(\mathrm{SOMe})=0.49\right]$ than sulfonium ion $\left[\sigma_{\mathrm{p}}\left(\mathrm{SMe}_{2}{ }^{+}\right)=0.90\right],{ }^{11}$ poorer anion solvating ability of $\mathrm{CH}_{2} \mathrm{Cl}_{2} / \mathrm{MMF}$ (4/6) than water, and better leaving group ability of chloride than sulfonium ion. All of these effects appear to disfavor the formation of a relatively stable carbanion intermediate required for the $(\mathrm{E} 1 \mathrm{cb})_{\mathrm{R}}$ mechanism,

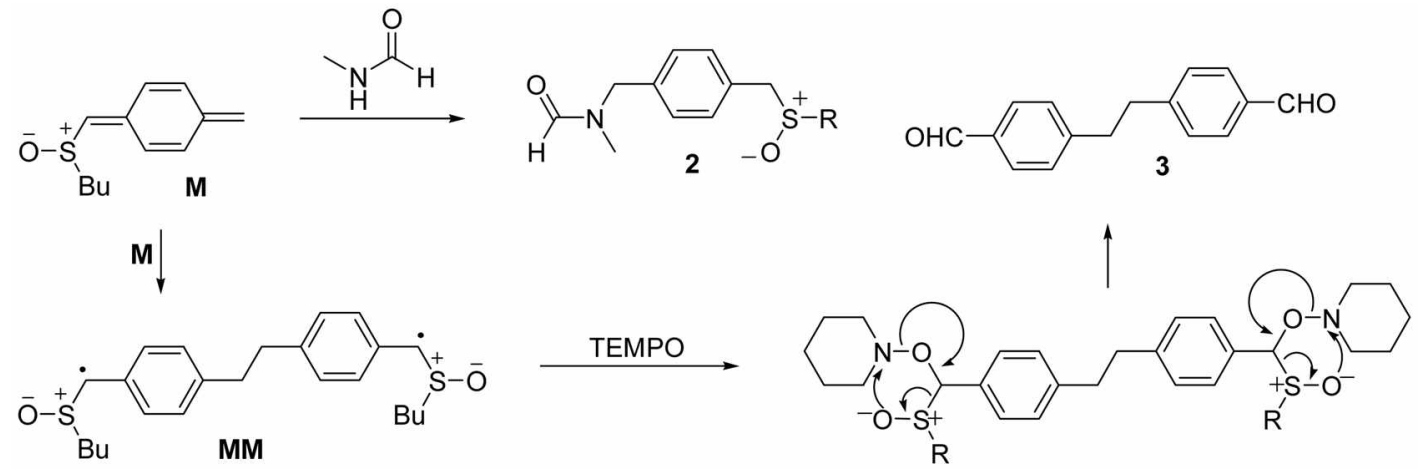

Scheme 2 


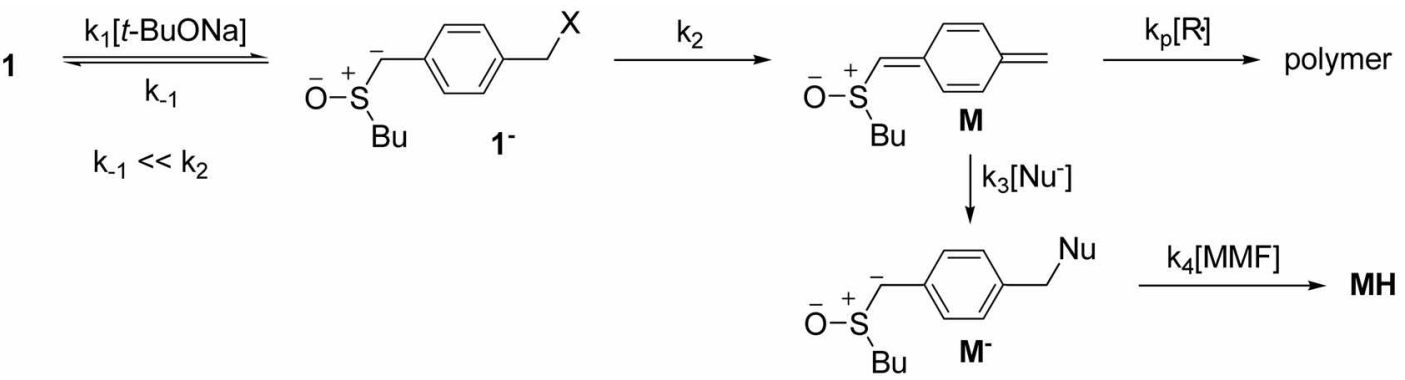

Scheme 3

leaving the $(\mathrm{E} 1 \mathrm{cb})_{\text {ir }}$ a favored alternative.

The rate equation for the formation of $\mathbf{M}$ can be expressed as $k_{\text {obs }}{ }^{\mathrm{E}}=k_{1} k_{2}[\mathbf{1 a}][t-\mathrm{BuONa}] /\left(k_{-1}+k_{2}\right)$. Assuming an (EIcb)irr mechanism (vide supra), i.e., $k_{-1} \ll k_{2}$, the equation can be simplified as $k_{\mathrm{obs}}=k_{1}[1 \mathrm{a}]\left[t-\mathrm{BuONa}\right.$. The value of $k_{1}$ can be taken from the slope of the plot in Figure 3, i.e., $k_{1}=0.44$ $\mathrm{M}^{-1} \mathrm{~s}^{-1}$, which is much larger than that of the reaction between $\mathrm{SH}$ and $\mathrm{OH}^{-}$(Scheme $1, k_{\mathrm{l}}=2.67 \times 10^{-3} \mathrm{M}^{-1} \mathrm{~s}^{-1}$ ). Because sulfinyl group is more weakly electron withdrawing than the sulfonium ion (vide supra), the large enhancement in $k_{1}$ can be attributed to the much stronger basicity of $t-$ BuONa in $\mathrm{CH}_{2} \mathrm{Cl}_{2} / \mathrm{MMF}$ (4/6) than $\mathrm{OH}^{-}$in water. It is to be noted that the $\mathrm{p} K_{\mathfrak{}}$ value of the alkoxide is increased by 12 $\mathrm{p} K_{\mathrm{a}}$ units as the solvent is changed from water to DMSO. ${ }^{12}$ Moreover, the rate data can explain why $\mathbf{M}$ is accumulated under the conditions of kinetic experiments. When [1a] = $8.00 \times 10^{-5} \mathrm{M}$ and $[t-\mathrm{BuONa}]=7.00 \times 10^{-2} \mathrm{M}$, the rate of production of $\mathbf{M}$ is $2.5 \times 10^{-6} \mathrm{M} \mathrm{s}^{-1}$. On the other hand, the rate of disappearance of $\mathbf{M}$ is $k_{\mathrm{cbs}}{ }^{\mathrm{P}}[\mathbf{M}]=8.00 \times 10^{-8} \mathrm{M} \mathrm{s}^{-1}$, if $[\mathbf{M}]=[1 \mathbf{a}]$. The rate of formation of $\mathbf{M}$ is much faster than that of its disappearance, that is, significant amount of $\mathbf{M}$ should be accumulated. This analysis indicates the reliability of the kinetic results.

Mechanism of Polymerization Reaction. There are two possibilities by which the intermediates $\mathbf{M}$ may undergo a polymerization reaction. If the reaction proceeds by the anionic mechanism, a nucleophile should be added to $\mathbf{M}$ to afford a carbanion, which may in tum propagate the polymerization. This requires a high reactivity of $\mathbf{M}$ toward a nucleophile. To assess this possibility, $2.0 \times 10^{-4} \mathrm{M}$ of $\mathrm{CH}_{3} \mathrm{NO}_{2}$ was added to a reaction mixture containing 1 a and $t-\mathrm{BuONa}$, and the rate of disappearance of $\mathbf{M}$ was monitored. Because the $\mathrm{p} K_{a}$ value of this carbon acid is 10.2 , it should be completely converted to the corresponding carbanion under the given reaction condition. ${ }^{13}$ Hence, if the carbanion is added to $\mathbf{M}$, the rate should increase. Indeed, the $k_{0 b s}{ }^{\mathrm{P}}$ increased by approximately $50 \%$ upon addition of $\mathrm{CH}_{3} \mathrm{NO}_{2}$ (Table 2), in accord with the slight increase of the $k_{0 b a}{ }^{\mathrm{P}}$ with [t-BuONa] (Table 1). The addition product $\left(\mathbf{M}^{-}\right)$may either initiate anionic polymerization or lead to side products with smaller MW. If $\mathbf{M}^{-}$propagates the anionic polymerization, the reaction should be quenched by the acid. In contrast, $k_{0 \text { oss }}{ }^{P}$ decreased only slightly when 1 equiv of $\mathrm{HCl}$ was added to the reaction mixture (Table 2). This result negates the possibility of anionic polymerization. In addition, the most likely fate of $\mathbf{M}^{-}$appears to be the abstraction of proton to afford MH (Scheme 3), which is a minor reaction pathway involving $\mathbf{M}$ as indicated by the modest increase in $k_{\mathrm{obs}}{ }^{\mathrm{P}}$ by the carbanion (Table 2).

On the other hand, the kinetic results are consistent with the free radical polymerization. First of all, the $k_{\mathrm{obs}}{ }^{\mathrm{P}}$ measured under this condition is similar to that reported for the reaction of SH and $\mathrm{OH}^{-}\left(k_{\text {obs }}{ }^{\mathrm{P}}=2.01 \times 10^{-3} \mathrm{~s}^{-1}\right)$. $^{7 \mathrm{n}}$ In addition, the rate increased by more than 15 -fold when a free radical initiator, $\mathrm{S}_{2} \mathrm{O}_{8}{ }^{2-}$, was added to the solution containing $\mathbf{M}$, and decreased by half upon addition of a free radical scavenger, TEMPO (Table 2). Moreover, the much larger enhancement in $k_{0 \text { obs }}{ }^{\mathrm{P}}$ by $\mathrm{S}_{2} \mathrm{O}_{8}{ }^{2-}$ than by the carbanion indicates that the free radical polymerization is the major reaction pathway involving M. Furthermore, convincing evidences in favor of the free radical mechanism have been reported for the polymerization reaction of $1{ }^{8 \mathrm{k}}$ First, free radical scavengers such as 2,2-diphenylpicrylhydrazyl (DPPH) and TEMPO almost stopped the polymerization. Second, the molecular weight of the polymer decreased by the addition of 2,4,5-triphenyimidazole radical, which would cause additional initiation and thereby lower the molecular weight. Third, the molecular weight decreased by the addition of $\mathrm{CBr}_{4}$, which is an excellent chain transfer agent for radical polymerization. Third, the side products 2 and 3 were isolated from the reaction mixture (Scheme 2). Therefore, it seems reasonable to conclude that the polymerization reaction of 1 with $t-\mathrm{BuONa}$ in $\mathrm{CH}_{2} \mathrm{Cl}_{2} / \mathrm{MMF}$ (4/6) proceeds by the $(\mathrm{E} I \mathrm{cb})_{u r}$ elimination-free radical polymerization mechanism via the $p$-quinodimethane intermediate $\mathbf{M}$ (Scheme 3).

To conclude, we have studied the mechanism of polymerization reaction of 1 with $t-\mathrm{BuONa}$ in $\mathrm{CH}_{2} \mathrm{Cl}_{2} / \mathrm{MMF}$ (4/ 6 ). The reaction proceeds by the (E1cb) ir elimination-free radical polymerization mechanisms via the $p$-quinodimethane intemnediate $\mathbf{M}$. The mechanism is similar to that shown in Scheme I for the PPV precursor polymer except that the first step is irreversible.

Acknowledgments. This work was supported by the Korea Science and Engineering Foundation (KOSEF) grant funded by the Korea Ministry of Education, Science, and Technology (No. R0A-2007-000-20027-0).

\section{References}

I. Roncali, J. Chem. Rev: 1997, 97, 173-205.

2. (a) Burroughes, J. H.; Bardley, D. D. C.; Brown, A. R.; Marks, R. 
N.; Mackay, K.; Friend, R. H.; Burns, P. L.; Holms, A. B. Nattre 1990, 347, 539-541. (b) Burns, P. L.; Holms, A. B.; Kraft. A.; Bradley, D. D. C.; Brown, A. R.; Frend, R. H.; Gymer, R. W. Nature 1992, 356, 47-49.(c) Hide, F.; Schwartz, B. J.; DaizGracia, M. A.; Heeger, A. J. Cheml. Phys. Lett. 1996, 256, 424427. (d) Smith, R. C.; Fisher, W. M.; Gin, D. L. J. Am. Chem. Soc. 1997, 119, 4092-4093.

3. (a) Wessling. R. A.; Zimmerman, R. G. U.S. Patent 3,401,152, 1968. (b) Wessling, R. A.; Zimmerman, R. G. U.S. Patent $3,532,643,1968 ; 3,705,677$, 1972. (c) Wessling, R. A.; Steeineri, W. J. U.S. Patent 3,408,525, 1968; 3,697,398, 1972, (d) Wessling, R. A. J. Polym. Sci., Polym. Symp. 1985, 72, 55-66.

4. (a) Gilch, H. G; Wheelwright. W. L. J. Polym. Sci. Part A: Pohtm. Chem. 1966, 4, 1337-1349. (b) Conticello, V. P.; Gin, D. L.; Grubbs, R. H. J. An. Chem. Soc. 1992, 114, 9708-9710. (c) Staring, E. G; Braun, D.; Rikken, G. L. J. A.; Demandt, R. J. C. E.; Kessener, Y. A. R. R.; Bouwmans, M.; Broer, D. Synth. Met. 1994, 67, 71-75. (d) Kraf, A.; Grimsdale, A. C.; Holmes, A. B. Angew. Chem. Int. Ed. 1998, 37, 402-428. (d) Wang, D.; We, P.; Wu, Z. Macroniol. 2000, 33, 6896-6898.

5. (a) McCoy, R. K.; Karasz, F. E.; Sarker, A.; Lahti, P. M. Chen. Mater: 1991, 3,941-947 and references therein. (b) Denton II, F. R.; Lahti, P. M.; Karasz, F. E. J. Polym. Sci. Part A: Polym. Chem. 1992, 30, 2223-223I. (c) Denton F. R.; Sarker, A.; Lahti, P. M.; Caray, R. O.; Karasz, F. E. J. Polym. Sci. Part A: Polym. Chem. 1992, 30, 2233-2240. (d) Lahti, P. M.; Modarelli, D. A. Denton III, F. R.; Lenz, R. W.; Karasz, F. E. J. Am. Chem. Soc. 1988, 110, $7258-7259$.
6. (a) Lenz, R.W.; Han, C. C.; Stenger-Smith, J.; Karasz, F. E. J. Polym. Sci. Part A: Polym. Chem. 1988, 26, 3241-3249. (b) Garay, R.; Lenz, R. W. Makronlol. Chent. (stippl) 1989, 5, 1-7. (c) Liang, W. B.; Lenz, R. W.; Karasz, F. E. J. Potym. Sci. Part A: Polym. Chem. 1990, 28, 2867-2875.

7. (a) Cho, B. R.; Han, M. S.; Suh, Y. S.; Oh, K. J.; Jeon, S. J. J. Chem. Soc. Chem. Commun. 1993, 564-566. (b) Cho, B. R.; Kim, Y. K.; Han, M. S. Mocronol, 1998, 31, 2098-2 106. (c) Cho, B. R.; Kim, T. H.; Kim, Y. K.; Kim, N. S. Macronol. 1999, 32, 35833589. (d) Cho, B. R.; Kim, T. H.; Son, K. H.; Kim, Y. K.; Lee, Y. K.; Kim, Y. K.; Jeon, S. J. Macromol, 2000, 33, 8167-8172.

8. (a) Issaris, A.; Vanderzande, D.; Gelan, J. Polymer 1997, 38, 2571-2574. (b) Issaris, A.; Vanderzande, D.; Adriaensens, P.; Gelan, J. Macromol. 1998, 31, 4426-443l. (c) Hontis, L.; Van Der Borght, M.; Vanderzande, D.; Gelan, J. Polymer 1999, 40, 66156617. (d) Hontis, L.; Vrindis, V.; Lutsen, D.; Vanderzande, D.; Gelan, J. Polymer 2001, 42, 5793-5796.

9. Gilchrist, T. L. Heterocyclic Chemistry, $2^{\text {nt }}$ ed.; Longman Scientific: London, 1992; p 22.

10. Gandler, J. R. The Chemistry of Dotble Bonded Futfotional Groups; Patai, S., Ed.; John Wiley and Sons: Chichester, 1989; vol. 2, part 1, pp 734-797.

11. Hine, J. Strictural Effects on Equilibria in Organic Chemistry, John Wiley and Sons, Inc.: New York, 1975; 066 .

12. Ametl, E. M.; Vankatasubremanian, K. G J. Org. Chem. 1983, 48, 1569-1578.

13. Carey, F. A.; Sundberg. R. J. Actanced Organic Chemistry; 3rd ed.; Plenum Press: New York, 1990; 411. 